\title{
The Effectivity of Supplementation Artemisia vulgaris for Adenocarcinoma Mammae Chemotherapy to Reduce CD 34 and Tumor Massa Diameter (Study in C3H Mice Given Adriamycin - Cyclophosphamide Chemotherapy)
}

\section{Bayu Teguh Saputro ${ }^{*}$, Selamat Budijitno²}

${ }^{1}$ Department of Surgery, Faculty of Medicine, Universitas Diponegoro, Semarang, Indonesia

${ }^{2}$ Department of Surgery Subdivision Oncology, Faculty of Medicine, Universitas Diponegoro, Semarang, Indonesia

\section{A R T I C L E I N F O \\ Keywords: \\ Artemisia vulgaris \\ Adenocarcinoma mammae \\ Microvascular density cd34 \\ Tumor mass diameter \\ *Corresponding author: \\ Bayu Teguh Saputro \\ E-mail address: \\ bayuteguh1984@gmail.com}

All authors have reviewed and approved the final version of the manuscript.

https://doi.org/10.32539/bsm.v5i7.337

\begin{abstract}
A B S T R A C T
Introduction. Breast cancer is still a major health problem in the world. In the case of breast cancer, surgery is the main treatment option besides chemotherapy, radiation, and immunotherapy such as Artemisia vulgaris (AV). AV is cytotoxic selectively acts as a supplement to breast adenocarcinoma chemotherapy given the Adriamycin-Cyclophosphamide regimen, to improve chemotherapy response.The study was aimed to proving AV extract enhances the chemotherapy response in $\mathrm{C} 3 \mathrm{H}$ mice with adenocarcinoma mammae given AdriamycinCyclophosphamide Chemotherapy. Method: This study used Post test only control group design on 24 females $\mathrm{C} 3 \mathrm{H}$ mice that were randomly selected and divided into four groups: group $\mathrm{K}$ (control), P1 (chemotherapy), P2 (extract), and P3 (combination). Adenocarcinoma mammae comes from the inoculation of donor mice. Chemotherapy of Adriamycin $60 \mathrm{mg} / \mathrm{m}^{2}$ and Cyclophosphamide $600 \mathrm{mg} /$ $\mathrm{m}^{2}$ were given in two cycles. AV $13 \mathrm{mg}(0.2 \mathrm{ml})$ was given once daily orally. CD34 were evaluated by imunohistochemical staining and tumor mass diameter were counted by calipers. Result: The microvascular density CD34 and tumor mass diameter were obtained in groups of $\mathrm{K}, \mathrm{P} 1, \mathrm{P} 2$, P3 respectively $60.76 \pm 1.5 ; 39.70$ $\pm 2.00 ; 57.10 \pm 1.29 ; 35.26 \pm 2.06$ and $12.52 \pm 1.49 ; 6.20 \pm 1.04 ; 9,94 \pm 1.21$; $3.94 \pm 0.76$. Statistical analysis showed significant differences in CD34 between groups $\mathrm{K}$ vs P1, P2, P3 ( $\mathrm{p}=0.001, \mathrm{p}=0.014, \mathrm{p}=0.001)$, P1 vs P2 and P3 ( $\mathrm{p}=$ $0.001, \mathrm{p}=0.033)$ and $\mathrm{P} 2(\mathrm{P}=0.001)$. Tumor mass diameter between groups $\mathrm{K}$ vs $\mathrm{P} 1$, P2, P3 ( $\mathrm{p}=0.001 ; \mathrm{p}=0.014 ; \mathrm{p}=0,001)$, P1 with P2 $(\mathrm{p}=0.001)$ P1 with P3 $(\mathrm{p}=$ $0.033)$ and $\mathrm{P} 2$ with $\mathrm{P} 3(\mathrm{p}=0.001)$. Correlation analysis between CD34 with tumor mass diameter was found to have significant correlation $(p=0.001$ and $r=0.932)$. Conclusion: Artemisia vulgaris is a potential to reduce angiogenesis in terms of decreasing the microvascular density $\mathrm{CD} 34$ and tumor mass diameter of adenocarcinoma mammae of $\mathrm{C} 3 \mathrm{H}$ mice treated with AdriamycinCyclophosphamide chemotherapy and can improve the effectivity.
\end{abstract}

\section{Introduction}

Cancer is one of the leading causes of death worldwide. Data from the International Agency for Research on Cancer (IARC) GLOBOCAN in 2012 noted that 1.7 million women were diagnosed with breast cancer or about $11.9 \%$ of all cancer incidence. WHO itself noted that the prevalence rate of breast cancer reached 6.3 million worldwide at the end of 2012.(1) The highest incidence of breast cancer is in the age group of more than 50 years, and the estimated incidence rate is around 2 among 1000 women per year. $(2,3)$

Cancer is basically not known with certainty, but it can be understood that this cancer is caused by 
malfunctioning in the cells in controlling cell growth. Cancer in general can be caused by disruption of the transcription process at the cellular level which results in uncontrolled cell division. in this case Nuclear Factor-Kappa B (NF-kB) has an important role in regulating regulation, including processes from inflammatory reactions, growth, formation of vascularity to oncogenesis. $(4,5)$

Angiogenesis factor plays an important role in the growth of cancer cells, progression and metastasis. The microvascular tissue complex of cancer guarantees an adequate supply of tumor cells with nutrients, oxygen and good drainage of metabolites. $(10,11)$ The process of forming new blood vessels can be identified as a clinical parameter of microvascular density through the expression of glycosylated transmembrane proteins namely Capillarity protein. Density (CD34) with a molecular weight of $116 \mathrm{kDa}$. The CD34 protein can differentiate hematopoytic cells from endothelial cells and lymphatic cells.(12)

The angiogenesis process involves NF- $\mathrm{kB}$ which is an important angiogenic growth factor that stimulates cancer cells to grow and causes metastasis of the tumor.(13) NF-kB and VEGF are the main growth factors in the blood vessels around the tumor and can cause metastasis.(14) related to providing the nutrients needed for tumor growth, invasion and metastasis.(15) The process of angiogenesis in tumors begins with the formation of capillary endothelial cells and this process is not found in normal cells. NF- $\mathrm{kB}$ can be an independent prognostic marker, because these vascular endothelial cells in tumor cells are more stable than normal cells, it could be a promising therapeutic target in new strategies for cancer therapy. (16)

In the process of breast cancer management, surgery is the main therapeutic modality. Other modalities include adjuvant therapy in the form of radiation and chemotherapy, especially if the resection is inadequate or there is metastasis. Some chemotherapy regimens commonly used for breast cancer are CAF / CEF (Cyclophosphamide, Adriamycin / Epirubicin, and 5 Fluorouracil), $\mathrm{CMF}$ (Cyclophosphamide, methotrexate and 5-Fluorouracil),
E-CMF (a combination of Epirubicin with CMF), MMM (Methotrexate mitozantrone, mitomycin). The response rate of each of the CAF regimens for all new therapies ranges from $20-40 \%$, but until now there has been no therapy that has achieved a 100\% response.(3) Efforts should be made to increase the effectiveness of therapy so that the response rate rate is needed. be increased so that the survival rate can be increased.

Many studies have been conducted in order to find effective and efficient solutions in the treatment of breast cancer patients. The Artemisia vulgaris plant contains artemisinin compounds which are known to have anti-cancer properties. Artemisinin, was isolated and extracted from the dried leaves and flower buds of Artemisia vulgaris. Artemisinin is a sesquiterpene lactone compound that contains an endoperoxide radical without containing nitrogen atoms in its chemical structure. $(17,18)$ Previous research was carried out on $\mathrm{C} 3 \mathrm{H}$ mice with liver carcinoma, at a dose of 100 mg / kg per day of artemisinin showing anticancer activity(19). Artemisinin contains an endoperoxide moety which can react with iron to form free radicals that are cytotoxic. $(20,21)$

This study was conducted to determine the effectiveness of Artemisia vulgaris extract as supplementation against mammary adenocarcinoma in terms of CD34 microvascular density and tumor mass diameter in $\mathrm{C} 3 \mathrm{H}$ mice receiving AdriamycinCyclophosphamide chemotherapy.

\section{Method}

\section{Research design}

This research is a laboratory experimental study with the design "Post test only control group design". The research subjects were divided into 4 groups, namely the group (1) control, tumor inoculated mice; (2) P1, the tumor inoculated mice, after the tumor arose, received chemotherapy Adriamycin Cyclophosphamide; (3) P2, the tumor inoculated mice, after the tumor arose, they received Artemisia vulgaris extract $13 \mathrm{mg} /$ times per day; P3, the mice were inoculated with tumors. After the tumor arose, they received AC chemotherapy and Artemisia vulgaris 13 
mg / times per day.

\section{Research samples}

The experimental animal was the $\mathrm{C} 3 \mathrm{H}$ strain mice (Mus musculus). Inclusion criteria: Female mice aged 8 weeks, inoculated with mammary adenocarcinoma, body weight 20-30 grams after acclimatization, no anatomical abnormalities were seen. Exclusion criteria: no tumor growth after inoculation, during inoculation and treatment the mice looked sick (movement was not active). The sample size according to WHO for each group is at least five animals with a reserve of $10 \%$, in this study the number of samples used per group was six mice.(11)

\section{Time and location of research}

Research and data collection were carried out for 5 months. The extract of Artemisia vulgaris was made at LPPT I, Faculty of Medicine, Gajah Mada University. The treatment of mice and the process of taking the tissue was carried out at LPPT IV, Faculty of Medicine, Gajah Mada University. The process of making paraffin blocks, HE staining and immunohistochemical staining were carried out at the Anatomical Pathology Laboratory, Faculty of Medicine, Sebelas Maret University, Surakarta.

\section{Operational definition}

Administration of Artemisia vulgaris: Artemisia vulgaris extract comes from the leaves extracted with ethanol solvent using the soxhletation method, with a dose of Artemisia vulgaris 100mg / kgBW / day orally (13mg / times). Administration of Adriamycin intravenously at a dose of $0.18 \mathrm{mg} /$ time. Administration of Cyclophosphamide is intravenously $1.8 \mathrm{mg} /$ time.

The microvascular density of CD34 tumors was a light brown color that appeared on the tumor capillaries after CD34 staining. The way to do the calculation is through the number of micro blood vessels per field of view which is calculated on five fields of view using 400x magnification.
The diameter of the tumor mass is used to show tumor growth. The diameter of the tumor mass was calculated by reducing the diameter of the tumor mass after and before treatment. The diameter of the tumor mass was measured using a tumor caliper tool, with an accuracy of $10^{-1} \mathrm{~mm}$ and measured in the largest onedimensional tumor diameter, in millimeters ( $\mathrm{mm})$.

\section{Materials and tools of research}

During the experiment, the experimental animals were placed in cages and given food and drink ad libitum. Mice underwent an adaptation period of one week before treatment

Tumors in donor $\mathrm{C} 3 \mathrm{H}$ mice will be inoculated in experimental animals for research and histopathological examination. Simplisia Artemisia vulgaris was obtained from the Biopharmaca Cultivation Conservation Unit, Center for Biopharmaca Studies, Bogor Agricultural University. The material used is Artemisia vulgaris extract, which is obtained by:(12)

a. One $\mathrm{kg}$ of dried leaves of Artemisia vulgaris is finely ground, then the resulting powder is put into a soklet device (capacity of $50 \mathrm{mg}$ ) and the extraction is carried out by soaking using ethanol solvent with a cycle of 8-10 times.

b. The extract was put into a rotary evaporator flask and vacuum distillation was carried out until it became concentrated (temperature $\left.40^{\circ} \mathrm{C}\right)$.

c. The extract was dried in an oven at $40^{\circ} \mathrm{C}$ for 1 hour to evaporate the ethanol.

d. The results obtained were $5.5 \mathrm{mg}$ of extract for every $1 \mathrm{~kg}$ of material $(0.55 \%)$ and the results were diluted with aquabidest until a concentration of $0.2 \mathrm{mg} / \mathrm{ml}$ was reached.

Tumors containing adenocarcinoma cells from donor $\mathrm{C} 3 \mathrm{H}$ mice were transplanted into recipient mice. The tumor from donor mice was then incised with a biopsy and a histopathological examination was performed to confirm the type of tumor. 


\section{Data analysis}

After all data has been collected, data cleaning, coding and data tabulation are carried out. The research data is processed and presented in the form of tables and box plots to see the distribution of data. The data collected was tested for normality using the Shapiro-Wilk test. If the data is normally distributed, it is followed by the ANOVA test to see if there is a difference in CD34 and the diameter of the tumor mass in the four groups. The magnitude of the differences in each treatment group was further analyzed by using the Post Hoc Test. The correlation test between the CD34 difference variable and the tumor mass diameter obtained a normal distribution tested by the Pearsons correlation test. The degree of significance limit was $\mathrm{p}$ $\leq 0.05$ with a $95 \%$ confidence interval. Data analysis was performed with SPSS Ver software. 21.0. for Windows.

\section{Ethical requirements}

This research always applies animal ethics. Before the research was carried out, the study had received approval from the Ethics Committee for Health Research, Faculty of Medicine, Diponegoro University.

\section{Results}

\section{Descriptive analysis}

\section{CD34 data description}

Each group K, P1, P2, P3 was taken as a sample and preparations were made to determine the microvascular density of the tumor by staining CD34. The results of measuring the average microvascular density value of the tumor can be seen in Table 1 .

The highest CD34 average was found in the control group, namely $60.76 \pm 1.53 \%$, while the lowest average CD34 was found in the P3 group, namely $35.26+$ $2.06 \%$. Likewise, the highest and lowest medians were found in the control group and the P3 group, namely $61.50 \%$ and $35.60 \%$, respectively. In the $\mathrm{P} 1$ and $\mathrm{P} 3$ groups with a population of $\mathrm{C} 3 \mathrm{H}$ mice who received $\mathrm{AC}$ chemotherapy, the average was $39.70+2.00 \%$ and $35.26+2.06 \%$, respectively.

\section{Tumor mass diameter data description}

Measurement of tumor mass diameter growth in group K (untreated), P1 (chemotherapy), P2 (extract) and P3 (combination) obtained the following results:

The box plot as shown in Figure 2 below shows the median growth of tumor mass diameter in the P3 group is lower than that of the P1, P2 and $\mathrm{K}$ groups.

The test for normality and homogeneity of CD34 microvascular density and tumor mass diameter for each group used the Shapiro-Wilk test. The normality and homogeneity test of groups K, P1, P2, P3 showed a value of $\mathrm{p}>0.05$. These results indicate that each group is normally distributed and the data is homogeneous.

\section{Microvascular density CD 34.}

The Shapiro-Wilk test showed that the CD34 data were normal and homogeneous, so it was continued with the One Way ANOVA statistical test, with the following results:

From the results of the One Way ANOVA test, it was found that the value of $p=0.000$, because $p<0.05$, it can be concluded that there is a significant difference in CD34 in the four groups. Henceforth, the Post Hoc test was used to determine the differences between groups. From the results of the Post Hoc test, it was found that there were significant differences between each group with a value of $\mathrm{p}<0.05$.

The diameter of the tumor mass. The Shapiro-Wilk test found that the tumor mass diameter data were normal and homogeneous, so that the One Way ANOVA difference test was continued.

The results of statistical tests using One Way ANOVA showed a significant difference in tumor mass diameter between groups $(p=0.001)$ so that it was followed by a post hoc test using Bonferroni with a significance value of $\mathrm{p}<0.05$. The results of the post hoc test showed a significant difference between group $\mathrm{K}$ and group P1, P2, P3 ( $\mathrm{p}=0.001 ; \mathrm{p}=0.044 ; \mathrm{p}=0.001$ ), group P1 with groups P2 and P3 $(p=0.001 ; p=0.033)$ and group P2 with P3 $(\mathrm{p}=0.001)$. 
The relationship between CD34 and the diameter of

the tumor mass

Assessment of the association between CD34 and tumor mass diameter was performed using the Pearsons parametric correlation test. The Pearsons test revealed a very strong association between CD34 and tumor mass diameter $(\mathrm{p}=0.001$ and $\mathrm{r}=0.932)$. Because the $\mathrm{p}$ value $<0.05$, it was concluded that there was a significant relationship between CD34 and tumor mass diameter, which was positive.

Table 1. Characteristics of CD34 data

\begin{tabular}{lccccc}
\hline Group & N & Min (\%) & Max (\%) & Mean \pm SD (\%) & Median (\%) \\
\hline K & 5 & 58.70 & 62.30 & $60.76 \pm 1.53$ & 61.50 \\
P1 & 5 & 36.70 & 41.60 & $39.70 \pm 2.00$ & 39.70 \\
P2 & 5 & 55.50 & 58.40 & $57.10 \pm 1.29$ & 57.20 \\
P3 & 5 & 32.40 & 37.70 & $35.26 \pm 2.06$ & 35.60 \\
\hline
\end{tabular}

Table 2. Characteristics of tumor mass diameter data

\begin{tabular}{lccccc}
\hline Group & N & Mean \pm SD (\%) & Median (\%) & Min (\%) & Max (\%) \\
\hline K & 5 & $12.52 \pm 1.49$ & 12.00 & 11.10 & 14.80 \\
P1 & 5 & $6.20 \pm 1.04$ & 6.20 & 4.90 & 7.50 \\
P2 & 5 & $9.94 \pm 1.21$ & 10.10 & 8.10 & 11.20 \\
P3 & 5 & $3.94 \pm 0.76$ & 4.00 & 2.90 & 4.80 \\
\hline
\end{tabular}

* The values in the table are the data on the growth of the tumor mass diameter in millimeters.

Table 3. Analysis of CD34 differences between treatment groups

\begin{tabular}{lcc}
\hline Group & Microvascular density (mean \pm SD) & P \\
\hline K & $60.76 \pm 1.53$ & \\
P1 & $39.40 \pm 2.00$ & $0.001^{*}$ \\
P2 & $57.10 \pm 1.29$ & \\
P3 & $35.26 \pm 2.06$ & \\
\hline
\end{tabular}

* Tested with One Way ANOVA (significant $\mathrm{p}<0.05$ )

Table 4. Post hoc analysis of CD34 microvascular density

\begin{tabular}{cccc}
\hline Group & P1 & P2 & P3 \\
\hline K & $0.001^{*}$ & 0.044 & $0.001^{*}$ \\
P1 & - & 0.001 & 0.001 \\
P2 & & - & $0.001^{*}$ \\
\hline
\end{tabular}

* Tested with Bonferroni (significant $\mathrm{p}<0.05$ )

Table 5. Analysis of differences in tumor mass diameter between treatment groups

\begin{tabular}{lcc}
\hline Group & $\begin{array}{c}\text { Tumor mass diameter (\%) } \\
\text { (mean } \pm \text { SD) }\end{array}$ & P \\
\hline $\mathbf{K}$ & $12.52 \pm 1.49$ & $0.001^{*}$ \\
\hline
\end{tabular}




\begin{tabular}{ll}
\hline P1 & $6.20 \pm 1.04$ \\
P2 & $9.94 \pm 1.21$ \\
P3 & $3.94 \pm 0.76$ \\
\hline
\end{tabular}

* Tested with One Way ANOVA (significant $\mathrm{p}<0.01$ )

Table 6. Post Hoc analysis of tumor mass diameter growth between groups

\begin{tabular}{lccc}
\hline Group & P1 & P2 & P3 \\
\hline K & 0.001 & 0.014 & 0.001 \\
P1 & - & 0.001 & 0.033 \\
P2 & & - & 0.001 \\
\hline
\end{tabular}

Table 7. Pearsons correlation test results

\begin{tabular}{lcc}
\hline Variable & $\mathbf{p}$ & $\mathbf{r}$ \\
\hline CD34 & 0.001 & 0.932 \\
The diameter of the tumor mass & &
\end{tabular}

* Tested with Bonferroni (significant $\mathrm{p}<0.05$ )

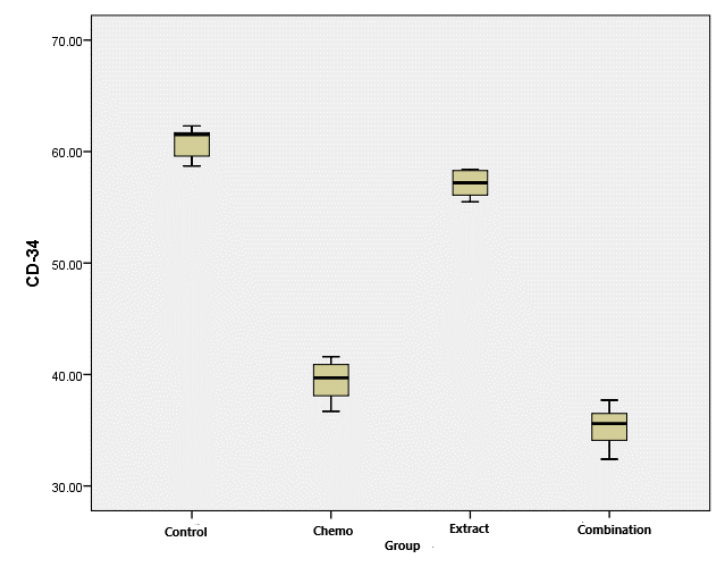

Figure 1. CD34 box plot graph

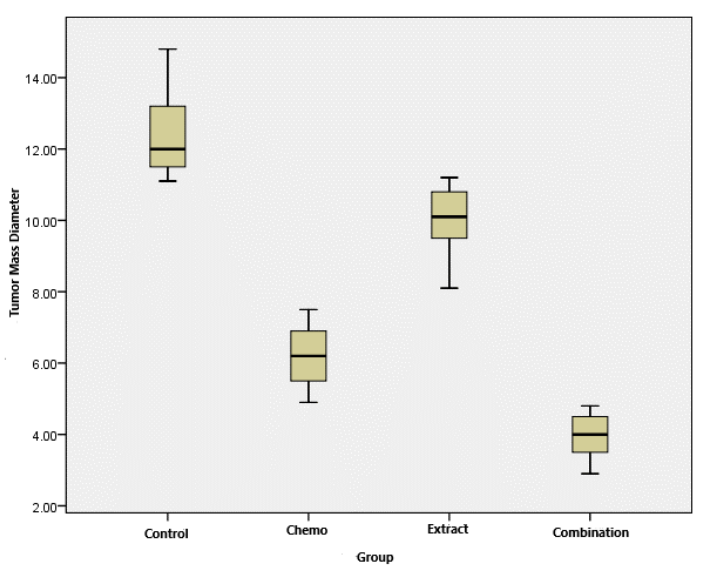

Figure 2. Box plot graph of tumor mass diameter 


\section{Discussion}

This study found the expression of $\mathrm{NF}-\mathrm{kB}$ in $\mathrm{C} 3 \mathrm{H}$ mice with mammary adenocarcinoma who received $\mathrm{AC}$ chemotherapy combined with Artemisia vulgaris extract was lower than that which was not combined. Thus, the first hypothesis is accepted. The Post Hoc test showed a significant difference in the comparison between the P1 and P3 groups $(\mathrm{p}<0.05)$. Data analysis of the CD34 microvascular density variable data was found to be lower in the group (P3) than in the group (P1). Based on these data, it can be concluded that the effect of Artemisia vulgaris extract can reduce CD34 and can have a synergistic therapeutic effect on the administration of AC chemotherapy.

The benefits of Artemisia vulgaris extract as an anticancer are caused by the activity of artemisinin compounds. This potential activity is related to the endoperoxide bonding of the artemisinin compound. The peroxide bridge from artemisinin will react with ferrous ions from tumor cells which will produce free radicals or ROS which will induce oxidative DNA cell damage resulting in apoptosis. $(23,24)$ This cell DNA damage is evidenced by decreased expression of $\mathrm{NF}-\mathrm{kB}$ which is a protein complex and acts as an important regulator of immune response, differentiation, cell proliferation, anti-apoptosis and angiogenesis. (25) The reduced expression of $\mathrm{NF}-\mathrm{kB}$ will cause a decrease in cellular activity. This process is caused by inhibited NF$\mathrm{kB}$ translocation activity to the cell nucleus, then the recruitment of other proteins (coactivators and RNA polymerases) will also be inhibited. (26)

Polyphenol compounds in medicinal plants have the ability to inhibit NF-kB. (30) Polyphenol compounds work to inhibit kinases by preventing phosphorylation or ubiquitination which causes degradation of IkB. This process further inhibits the translocation process of $\mathrm{NF}-\mathrm{kB}$ to the cell nucleus. (31) As a result, there is inhibition of NF- $\mathrm{kB}$ in the NF-kB-DNA complex. (32)

Post Hoc test on a population of $\mathrm{C} 3 \mathrm{H}$ mice with mammary adenocarcinoma receiving AC chemotherapy, namely groups $\mathrm{P} 1$ and $\mathrm{P} 3$ obtained $\mathrm{p}$ $<0.05$. These results indicate that there is a significant difference in the comparison between the P1 and P3 groups. By using the Pearsons correlation analysis between CD 34 and tumor mass diameter in the P1 and P3 groups, the correlation coefficient $\mathrm{r}=0.932$ with $\mathrm{p}$ $<0.05$. There is a very strong association between CD34 and tumor mass diameter in $\mathrm{C} 3 \mathrm{H}$ mice with mammary adenocarcinoma given combination chemotherapy Adriamycin-Cyclophosphamide and Artemisia vulgaris extract. Thus, the third hypothesis is accepted.

Other studies suggest that artemisinin compounds and their derivatives can inhibit angiogenesis, through inhibition of cell proliferation, migration, formation of tube formation in endothelial cells. (38) The inhibition process which reduces the microvascular density of tumors is triggered by inhibition of the NF- $\mathrm{kB}$ pathway which causes downregulation of VEGFR2. VEGF and VEGFR2 are major regulators of the angiogenesis process. The blockade of the NF-kB pathway by artemisinin against the VEGFR2 promoter will inactivate transcription activity, so that proteins that play a role in angiogenesis are not formed. (39) As a result, the growth in the diameter of the tumor mass decreases.

CD34 and tumor mass diameter growth has a very strong relationship. $\mathrm{NF}-\mathrm{kB}$ is a protein that functions to regulate the formation of blood vessels when they translocate into the cell nucleus. The transcription factor $\mathrm{NF}-\mathrm{kB}$ is activated when there are proinflammatory cytokines including TNF-a which will activate $\mathrm{NFkB}$, causing VEGF production and VEGFR expression to increase with clinical parameters in the form of increased CD34 microvascular density $(25,40,41)$. This angiogenesis process can be assessed through clinical parameters in the form of microvascular density, an increase in angiogenesis activity will show an increase in microvascular density which has an impact on tumor size growth.

The results showed that the administration of Artemisia vulgaris extract had a synergistic effect on the administration of AC chemotherapy in a population of $\mathrm{C} 3 \mathrm{H}$ adenocarcinoma mammae mice. This suggests that Artemisia vulgaris can be given as a supplement to AC chemotherapy. 


\section{Conclusion}

Artemisia vulgaris extract has a synergistic effect by administering Adriamycin-Cyclophosphamide in increasing chemotherapy response by reducing CD34 microvascular density and decreasing the diameter of tumor mass in $\mathrm{C} 3 \mathrm{H}$ mice with adenocarcinoma mammae.

\section{Conflict of interest and funding.}

The author does not receive funding or profit from industry or other places for conducting this research.

\section{References}

1. Ferlay J, Soerjomataram I, Ervik M, Dikshit R, Eser S, Mathers C, Rebelo M, Parkin DM, Forman D, Bray, F. GLOBOCAN 2012 v1.1, Cancer Incidence and Mortality Worldwide: IARC Cancer Base No. 11 [Internet]. Lyon, France: International Agency for Research on Cancer; $2014 . \quad$ Available from:http://globocan.iarc.fr, accessed on $16 / 01 / 2015$.

2. World health statistics 2008. Breast cancer : mortality and screening. Dikutip dari: URL : http: / / www.who.int

3. Chen F, Castranova V, Shi X. New insights into the role of nuclear factor-kappaB in cell growth regulation. Am J Pathol 2001;159: 387-97.

4. Karin M, Cao Y, Greten FR, Li ZW. NF-kappa B in cancer: from innocent by stander to major culprit. Nat Rev Cancer 2002; 2:301-10.

5. Escarcega RO, Fuentes Alexandro S, García Carrasco M, Gatica A, Zamora A. The transcription factor nuclear factor-kappa B and cancer. Clinical Oncology March 2007; 19 (2): 154-61.

6. Zhou HJ, Wang WQ, Wu GD, Lee J, Li A. Artesunate inhibits angiogenesis and downregulates vascular endothelial growth factor expression in chronic myeloid leukemia K562 cells. Vascul. Pharmacol 2007; 47: 131213.
7. Hina Manzoor, Muhammad Imran Qadir, Khizar Abbas, Muhammad Ali. Vascular endothelial growth factor (VEGF) In Cancer.African Journal Of Pharmacy and Pharmacology 2014 ; 1-4.

8. Naz S, Qadir MI, Shirazi KH. Nanotechnology for imaging and drug delivery in cancer. $J$ Chem. Soc.Pak 2012; 34: 107-11.

9. Kerbel SR. Molecular Origins of cancer"tumor angiogenesis". N Engl J med 2008; 19: 358411.

10. Tu Y.Y. The discovery of artemisinin (qinghaosu) and gifts from Chinese medicine. Nat. Med 2011; 17:1217-20.

11. Weifeng T, Feng S, Xiangji L, Changqing S, Zhiquan Q, Huazhong Z, Peining Y, Yong Y, Mengchao W, Xiaoqing $J$, Wan-Yee L. Artemisinin inhibits in vitro and in vivo invasion and metastasis of human hepatocellular carcinoma cells. Phytomedicine 2011; 18: 158-62.

12. H. Lai, T. Sasaki, and N.P. Singh. Development of artemisinin compounds for cancer treatment. The Journal of New Anticancer Agents. Vol 20.No2. March 2015;1.

13. Chattopadhyay M, Kodela R, Nath N, Barsegian A, Boring D. Hydrogen sulfide-releasing aspirin suppreses NF-kB signaling in estrogen receptor negative breast cancer in vitro and in vivo. Biochemical Pharmacology 2012; 83: 723-32.

14. Kong R, Jia G, Chen Z.X, Wang Y.W, Mu M, Wang, S.J, Pan, S.H, Gao Y, Jian H.C, Dong D.L. et al. Dihydroartemisinin enhances Apo2L/TRAIL-mediated apoptosis in pancreatic cancer cells via ROS-mediated upregulation of death receptor 5. PLoS ONE 2012, 7, e37222.

15. Liu M, Sakamaki T, Casimiro MC, Willmarth NE, Quong AA, Ju X, et al. The canonical NF$\mathrm{kB}$ pathway governs mammary tumorigenesis in transgenic mice and tumor stem cell expansion. Cancer Res 2010 ;15:70(24): 10464 73. 
16. Figuera-Losada M., Rojas C., Slusher B. S.. Inhibition of microglia activation as a phenotypic assay in early drug discovery. J. Biomol. Screen. 2014; 19: 31-17.

17. Karin M. NF-kB as critical link between inflammation and cancer. Cold Spring Harb Perspect Biol. 2010; 1.

18. Lerman C, Shields A. Genetic testing for cancer susceptibility: the promise and the pitfalls. Nature Rev cancer. 2004; 4:p.235-41.

19. Ruiz P. A., Haller D. Functional diversity of flavonoids in the inhibition of the proinflammatory NF-kappaB, IRF, and Akt signaling pathways in murine intestinal epithelial cells. J. Nutr. 2006; 136, 664-671.

20. Qiang M, Krista K, Jianping Y, Bruce J. C. Inhibition of Nuclear Factor B by Phenolic Antioxidants: Interplay between Antioxidant Signaling and Inflammatory Cytokine Expression. Mol Pharmacol 64:219 -211.

21. Mansilla, S. dan Portugal J. Sp1 transcription factor as a target for anthracyclines: effects on gene transcription. Biochimie 2008; 90(7): 976-87.

22. Ruiz-Ruiz C, Robledo G, Cano E, Redondo JM, Lopez-Rivas A. Characterization of p53mediated up-regulation of CD95 gene expression upon genotoxic treatment in human breast tumor cells. J Biol Chem, 2003; 278(34): 31667-75.

23. Licata S, Saponiero A, Mordente A, Minotti G. Doxorubicin metabolism and toxicity in human myocardium: role of cytoplasmic deglycosidation and carbonyl reduction. Chem Res Toxicol 2000; 13(5): 414-20.

24. Skeel RT, Kleif SN. Biologic and pharmacologic basis of cancer chemotherapy and biotherapy. In : Skeel RT. Handbook of cancer chemotherapy, $7^{\text {th }}$ Ed. Philadephia (USA): Lippincott William and Wilkins 2007; 37-41.

25. D'Alessandro $\mathrm{S}$, Basilico $\mathrm{N}$, Corbett $\mathrm{Y}$, Scaccabarozzi D, Omodeo-Sale F, Saresella M, Marventano I, Vaillant M, Olliaro P, Taramelli D. Hypoxia modulates the effect of dihydroartemisinin on endothelial cells. Biochem Pharmacol 2011; 82:476-84.

26. Wang SJ, Sun B, Cheng ZX, Zhou HX, Gao Y, Kong $\mathrm{R}$, et al. Dihydroartemisinin inhibits angiogenesis in pancreatic cancer by targeting the NF-kappaB pathway. Cancer Chemother Pharmacol 2011; 68:1421-30.

27. Aggarwal BB, Shishodia S. Molecular targets of dietary agents for prevention and therapy of cancer. Biochem Pharmacol 2006; 71 : 13971421.

28. Yance D. Cancer and inflammation: the emerging role of botanical compounds in targeting proinflammatory pathways, with particular attention to the $\mathrm{NF}-\mathrm{kB}$ signaling pathway. Diakses tanggal 6 April 2010. Dari:http:/ / www.centrehealing.com/files/NF$\mathrm{kBpaper}$.pdf. 